\title{
The efficiency of use of energy saving technologies in construction
}

\author{
Natalya Trukhina ${ }^{1}$ and Ella Okolelova ${ }^{1, *}$ \\ ${ }^{1}$ Voronezh State Technical University, 20-let Oktyabrya str., 84, 394006, Voronezh, Russia
}

\begin{abstract}
The article considers problems and prospects of development of energy saving technologies in construction. The possible directions of improving the construction of residential facilities with the aim of increasing their efficiency are considered, taking into account different technologies. The main emphasis is on the use of solar panels as one of the most effective ways of saving resources. The maximum level of heliotropia for the Central black earth region is determined. To increase the efficiency of the solar battery it is proposed to develop a rotary device that allows you to change the angle of the battery in the vertical and horizontal planes. The dynamics of rotation in the horizontal plane should depend on the time of day, in the horizontal - season. The article presents the problem of determining the speed of rotation of the solar battery in the direction of the solar azimuth and relative to the horizon during the day, allowing you to use a slewing device with maximum efficiency. Increase efficiency when using the rotary mechanism will reduce the number of solar batteries with the same capacity of electricity consumption. Also the problem of determining the optimal number of solar panels.
\end{abstract}

\section{Introduction}

Today, more attention is paid to environmental issues. Growing city, which are developing not only residential and recreational areas, but also the industry. Built up vacant lots, and new site that allows you to expand urban areas, provides positive dynamics of production, creates new jobs, develops infrastructure, which ultimately increases the social level of life.

On the other hand, there are very few places not yet cut forests, where the clean waters and flowery meadows. The process of urban sprawl on the availability of the territory is irreversible. Urbanization has reached, if not a limit, it is at least close to the critical maximum. But only if the construction affects the environmental situation? Unfortunately, no. Consider environmental problems from the standpoint of saving resources and energy saving technologies. Problems of energy saving today, not simply come in first place in resolving many important issues, but also begin to occupy a dominant position. This is particularly relevant issue for the construction industry. For decades the question of the use of energy efficient and energy saving technologies in construction, there's a great world construction experience "active", "passive", "smart" homes [1-5].

Unfortunately, in Russia, a similar construction is still at a very low level.

${ }^{*}$ Corresponding authors: ella.o2011@yandex.ru 


\section{State-of-the-Art}

Consider possible ways of improving the construction of residential facilities with the aim of increasing their efficiency, taking into account different technologies. The most common currently include the following [1]:

I. Technology

1. Cladding structures (vented facades)

2. Constructive elements of buildings with low thermal conductivity

3. Effective thermal insulation materials

4. Finishing materials

5. System adjustable ventilation

II. Electrotechnology

1. Energy saving lighting

2. Renewable energy sources (solar panels, wind energy)

III. Gidrotekhnologii

1. Installation of instrumentation

2. Collection and purification of rainwater for technical needs.

3. The collection of wastewater for reuse and installation of the filtration system.

Each alternative technology has a certain level of efficiency. As a rule, the efficiency can be detected within a certain period of use, when there is a decrease in the consumption of resources.

The purpose of development of this direction of energy saving is the reduction of costs in energy-efficient systems in the country for domestic needs of the vast number of consumers, which are private and apartment buildings, neighborhoods, towns and cities [6, 7].

For these of diverse size and energy consumption of the objects must lead in design view saving and konstruktivnye instrument base solar storage systems.

There is the possibility of using solar panels as one of the most common and efficient way of developing energy efficient technologies based on renewable sources of energy to provide buildings with the necessary amount of heat.

Despite the fact that the geographical conditions of construction in Russia are very diverse, many regions are in the latitude with enough Sunny days to make use of this priceless energy.

Solar panels have become widespread in many countries of the world. This is especially true for climates with high annual insolation [8-11].

In Russia, despite the existence of geographic areas with relatively warm climate, where the annual level of insolation is high enough, the solar batteries are not widespread. The main factor hindering the development of such energy saving technologies is their high cost.

Unfortunately, this is not the only disadvantage of solar panels. A significant negative indicator is the low efficiency. Currently, the efficiency of solar cells is at the level of 11-16 $\%$, which is extremely low. Efficiency varies with the magnitude of insolation, solar power battery, as well as the important role played by the angle of the battery [12].

In connection with these terms of limitations it is impractical to cover the entire surface of the roof with solar cells, which leads to the increase of costs. It is sufficient to determine the rational combination of the area of coverage with maximum effect and minimum production of resources for the purchase, installation and operation of solar panels.

The value of efficiency directly depends on the angle of incidence of sunlight on the photocell. The most effective is the direct angle of sunlight [13]. Therefore, the use of stationary solar panels in horizontal, vertical and inclined planes does not allow you to maximize the storage of solar energy (Fig. 1). 


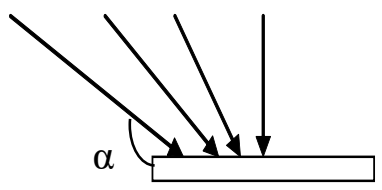

a) Horizontal plane

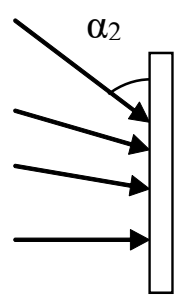

b) Vertical plane

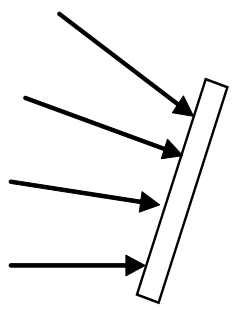

c) The Inclination relative to the horizontal plane

Fig. 1. The position of the solar panels.

Therefore, the maximum level of heliotropiaceae will be in the case of direct sunlight on the solar cell. When you install solar energy systems with a focus on the southern direction, the calculations show that to obtain the maximum amount of solar radiation the angle of surface inclination to the horizontal plane $\alpha$ has to be $34^{\circ}$ for winter (December - February) $\alpha=73^{\circ}$ for the summer (June - August), during year-round use of the solar $\alpha=54^{\circ}$.

It is important when designing buildings to consider the installation of a storage solar system with South orientation.

The maximum amount of solar energy under the given conditions of the location of the system relative to the horizontal plane will be achieved in the period of day 10 to 14 hours. At this time receives around $99 \%$ of solar energy.

According to the observations of the dependence of insolation from changes in solar azimuth determined that after 17 hours of loss of heliotropiaceae will be in the summer, 15 $30 \%$ and $10-20 \%$ in winter. The maximum effect possible in the case where the solar panel will be rotated by the solar azimuth, and also relative to the horizon. Only in this case the sun's rays will be directed perpendicular to the panel and the effect of heliotropiaceae will be greatest.

To increase the efficiency of the battery it is proposed to develop a rotary device that allows you to change the angle of the battery in the vertical and horizontal planes. The dynamics of rotation in the horizontal plane should depend on the time of day, in the vertical - season.

Increase efficiency when using the rotary mechanism will reduce the number of solar batteries with the same capacity of electricity consumption. Particularly important is the accumulation of energy in the period of active insolation, when it is possible to significantly increase energy savings. For this purpose, the tasks, for determining the angle and speed of rotation of the solar panels to maximization efficiency.

It is necessary to determine the speed of rotation of the solar battery in the direction of the solar azimuth and relative to the horizon during the day.

Let us assume the following assumptions:

1. the calculation is performed for the warm season with the maximum level of insolation;

2. the change efficiency of solar panels during the day is normal.

3. let the maximum efficiency of the battery is $20 \%$. During the day it ranges from 0 to $20 \%$ between the solar azimuth.

The next step defines the problem of finding the speed of rotation of the plane of the battery around its axis with the rotation of this axis (Fig. 2). 


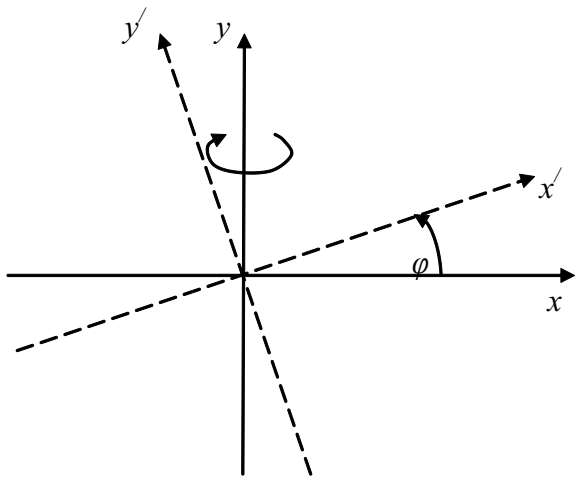

Fig. 2. The rotation of the battery housing around its axis rotated.

Consider the rotation of an object in the plane xoy.

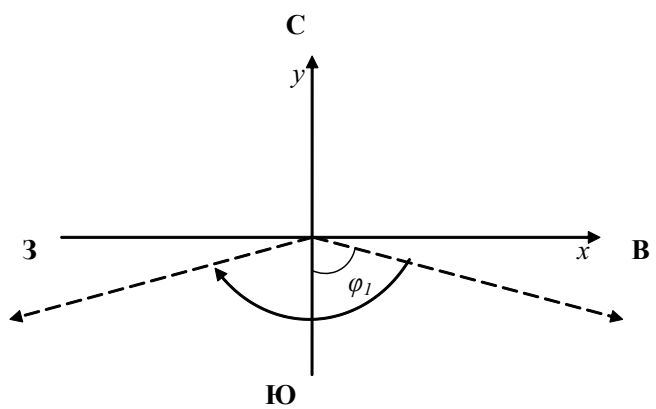

Fig. 3. Rotating the battery around the vertical axis z.

The angle $\varphi 1$ shows the value of the solar azimuth. When describing the rotation of the battery in three-dimensional space will receive that rotation occurs around the $\mathrm{z}$ axis.

To comply with the conditions of the maximum effect of energy requires that the solar panel is perpendicular to the direction of sunlight. Therefore, it is necessary to consider a rotation in its plane relative to the horizon line, that is, rotation about the $\mathrm{x}$-axis.

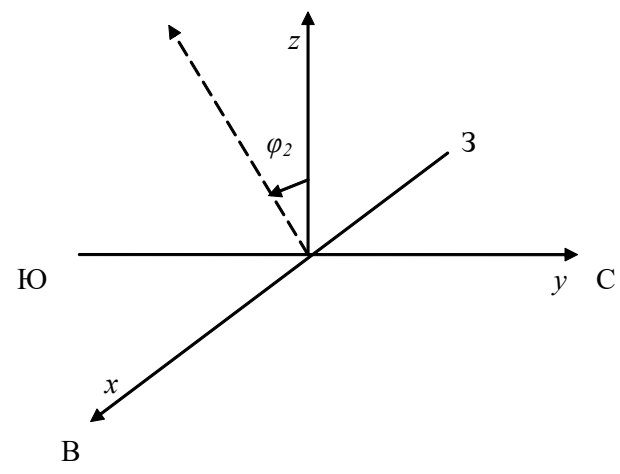

Fig. 4. Rotating the battery around the $x$-axis.

The angle $\varphi 2$ indicates the height of the sun above the horizon during the year. We form the rotation matrix.

Rotation around the $\mathrm{x}$ axis: 


$$
M_{x}(\varphi)=\left|\begin{array}{ccc}
1 & 0 & 0 \\
0 & \cos \varphi & -\sin \varphi \\
0 & \sin \varphi & \cos \varphi
\end{array}\right|
$$

Rotation around the $y$ axis:

$$
M_{y}(\varphi)=\left|\begin{array}{ccc}
\cos \varphi & 0 & \sin \varphi \\
0 & 1 & 0 \\
-\sin \varphi & 0 & \cos \varphi
\end{array}\right|
$$

Rotation around the $\mathrm{z}$ axis:

$$
M_{z}(\varphi)=\left|\begin{array}{ccc}
\cos \varphi & -\sin \varphi & 0 \\
\sin \varphi & \cos \varphi & 0 \\
0 & 0 & 1
\end{array}\right|
$$

In fact, the rotation occurs in a plane parallel to the y-axis. After transformations we get:

$$
\begin{gathered}
x^{\prime}=x \\
y^{\prime}=y \cos \varphi+z \sin \varphi, \\
z^{\prime}=-y \sin \varphi+z \cos \varphi .
\end{gathered}
$$

Determine the angular velocity of rotation in three-dimensional space. Set the object's rotation, time-varying, the size of the angle $\varphi(t)$ and the ORT of the axis $\vec{n}(t)$. Then the angular velocity is equal to

$$
\vec{\omega}=\vec{n}(t)+\vec{n} \sin \varphi+\vec{n} \times \vec{n}(1-\cos \varphi)
$$

where $\vec{n}=[x ; y ; z]$ - the vector defining the axis around which the rotation of the coordinate system by the angle $\varphi$.

Depending on what the settlement is designing the installation of solar panels, accepts data for solar azimuth and altitude solstice for the corresponding coordinates.

These angles define limits of rotation of the solar panel in the vertical plane.

Thus, it is possible to calculate the required trajectory of the rotation of the solar battery during the day and throughout the year for different latitudes.

\section{Results}

You need to determine the optimal number of solar panels.

The calculation is carried out from the condition of the average monthly consumption and stock reliability in two days without the active sun $(\mathrm{K})$.

Original data:

- TV power $\mathrm{P}=100$ watts $\mathrm{t}=5$ hours a day and 7 days a week.

- Lighting devices with total capacity of $\mathrm{RA}=1000 \mathrm{~W}, \mathrm{t}=6$ hours a day and 7 days a week.

- Illumination solar panel: T -7,8 hours a day (latitude Rostov-on-don, summer).

- Efficiency of the inverter is 0.9 .

- Feature one battery: $\mathrm{Sa}-225 \mathrm{~A} / \mathrm{h}, \mathrm{U}-12 \mathrm{~V}$. 
- The level of discharge of the battery and 0.7 .

When the total power of the devices $1100 \mathrm{~W}$ average power consumption will be $\mathrm{WH}_{\mathrm{H}}=$ $45,500 \mathrm{kWh}$ per week, or $\mathrm{W}=6,500 \mathrm{kWh}$ per day. For the exact calculation requires to take into account the probability of simultaneous use of the devices, peak and reactive load or distribution of load during the day.

Total power of consumers choose $1,1 \mathrm{~kW}$ inverter power $2 \mathrm{~kW}$ (with the prospect of growth and compensate for unaccounted loads). The input voltage of the inverter Uins -24 V.

The total daily load on the inverter in the Ah, given the efficiency of the inverter:

$$
I_{\text {inb }}=\frac{W_{c}}{U_{\text {inb }} \cdot E F F I C I E N C Y}=\frac{6500}{24 \cdot 0,9}=300,9 \mathrm{Ah}
$$

This value is important for determining the amount of battery current charging and, ultimately, system reliability.

In our case:

- Current load is doubled to provide two days of supply.

- Take into account the permissible depth of discharge of battery is 0.7 .

- Get total load current:

$300,9 \times 2 \times 0.7=421,26$ A.

Taking into account the characteristics of one battery of $\mathrm{Sa}=225 \mathrm{~A} \bullet \mathrm{h}$, we obtain the number of battery modules voltage $24 \mathrm{~V}$ (voltage inverter) 421,26/225 $=1,87$. Rounded to 2 . in order to get Ua (12) on one battery connected in one unit, two batteries in series. Total turns of 2 parallel connected unit, composed of two batteries each. Only 4 of the battery.

In addition to the load of the consumer, you need to add the load, taking into account the recharging of the batteries. It is $10 \%$ of the total capacity of the battery module $(4 * 225 * 12)$ $=10800 \mathrm{~W} \cdot \mathrm{h} * 10 \% 108 \mathrm{WH}$. Total average daily consumption will be $-6500+108=6608$ $\mathrm{W} \cdot \mathrm{h}$

\section{Discussion}

Problematic points in this scheme are not only the introduction of solar energy, with its high financial cost of getting power to lighting and heating, but also issues of heat insulation of the heated objects. It aims not only to heat but also to preserve and efficiently store it in the volume of the building, reducing the cost of generation. One of the effective solutions to construction technology is the construction of buildings and their enclosing wall constructions from monolithic heat-insulating lightweight concrete class of cellular concrete, foam concrete, aerated concrete, etc. types. These materials are not only effective thermal insulation, they are cheap, technologically available raw materials and most importantly environmentally friendly.

Their thermal properties and structure create the most comfortable atmosphere on the inside. This is due to the properties of these materials to pass through its structure and output of excess moisture from indoor air [14-16]. Preserving heat and comfortable humidity equals on the performance characteristics of these materials to the wood. The essential point of this system is ventilation, i.e. the problem of cleaning (filtering), processing (decontamination) and air convection in our buildings, homes and apartments with modern systems of ventilation and conditioning.

Their correct design and application in the ecology of dwellings, especially in urban areas, it is necessary to pay great attention. We see the solution to the problem of hanging energy conservation in a comprehensive approach to this global problem, which means careful, in- 
depth study of each kompanent of the entire system and the adoption of effective engineering solutions for each of the considered issues.

All these factors contribute to more correct strategic development of construction including the reduction of energy consumption, energy from renewable sources, creating environmentally friendly and comfortable housing for people.

\section{Conclusion}

To ensure that the system energy solar battery for the light ( $\mathrm{T}=7,8$ hours) to produce the average daily demand for electricity $(6608 \mathrm{~W} \cdot \mathrm{h})$. Therefore, a block of solar modules (with output voltage of $24 \mathrm{~V}$ and capacity of 200 watts each) must consist of 4 modules $(6608 / 7,8 /$ $200=4,2$ ).

Thus, for energy supply of a consumer with the active power $1100 \mathrm{~W}$ requires 4 modules of solar cells with output parameters: $\mathrm{Wmax}=200 \mathrm{~W}$ and $\mathrm{U}=24 \mathrm{~V}$.

Overall dimensions of this equipment and its placement on the objects, the cost of its creation and installation, requires a different attention to the question of heat insulation of our buildings, in view of the high cost of development in this direction.

\section{References}

1. E.Y. Okolelova, R.D. Zilberov, Economics and management control systems 1.1(11), 126-130 (2014)

2. An. Mottaeva, V. Lukinov, As. Mottaeva, Strategy of management of the state and municipal ownership: theory and practice (Moscow, MGSU, 2015)

3. E.Y. Okolelova, R.D. Zilberov, Economics and management control systems 1.1(11), 156-161 (2014)

4. N.I. Trukhina, V.N. Barinov, FES: Finance. Economy. Strategy 2, 42-46 (2012)

5. O.V. Kornicka, E.Y. Okolelova, N. Trukhina, Management of economic systems: electronic scientific journal 12(60), 93 (2013)

6. An. Mottaeva, World of economy and law 11, 15-18 (2010)

7. A.P. Dzyuba, Energy, 3 (2017)

8. S.Yu. Pleshkov, L.G. Pastukhov, Vestnik of Astrakhan state technical University 2, 60 (2015)

9. A.S. Vilkova, K.A. Petulko, Young scientist 8, 1268-1271 (2016)

10. S.G. Sheina, R.D. Zilberov, Economics and management of control systems 2(12), 110116 (2014)

11. An. Mottaeva, As. Mottaeva, Economy and entrepreneurship 3-2(56-2), 98-102 (2015)

12. P.G. Hrabove, E.Y. Okolelova, N.I. Trukhina, Technology of textile industry 1(367), 78 82 (2017)

13. N.I. Trukhina, E.A. Pogrebennaya, Labour and social relations 3, 57-62 (2010)

14. E. Chibisova, T. Meshcheryakova, Science Krasnoyarya, 6 (2-2), 146-148 (2017)

15. V. Lukinov, A. Mottaeva, Online magazine of science 2(21), 54 (2014)

16. N.I. Trukhina, E.A. Pogrebennaya, Organizational and economic mechanism of planning and control in the management of the housing estate. Monograph (Growth. builds state University, Rostov - na - Donu, 2010) 